\title{
Acil Kliniklerde Çalışan Hemşirelerin Problem Çözme Becerilerinin İncelenmesi
}

\author{
Investigation of The Problem Solving Skills of Nurses Working in Emergency Clinics
}

Özlem ŞAHIN AKBOĞA ${ }^{1}$, Sevban ARSLAN ${ }^{2}$

\begin{abstract}
ÖZ
Araştırma, acil kliniklerde çalışan hemşirelerin problem çözme becerilerini belirlemek amaciyla yürütülmüştür. Tanımlayıcı ve kesitsel olan bu çalışma, Ocak 2016-Haziran 2016 tarihleri arasında, Adana Çukurova Üniversitesi Tip Fakültesi Balcalı Hastanesi, Adana Numune Eğitim ve Araştırma Hastanesi, Yozgat Bozok Üniversitesi Sağlık Uygulama ve Araştırma Merkezi ile Yozgat Şehir Hastanesi'nin acil kliniklerinde çalışan ve araştırmaya katılmayı kabul eden 120 hemşire ile yürütülmüştür. Verilerin toplanmasında, "Tanıtıcı Bilgi Formu" ile "Problem Çözme Envanteri” kullanılmıştır. Verilerin değerlendirilmesinde, tanımlayıcı istatistikler ve ANOVA testi kullanılmıştır. Acil klinikte çalışan hemşirelerin \%74,27'sinin problem çözme ile ilgili eğitim almadığ $\breve{1}_{1}$ ve $\% 55,8$ 'inin problemin kaynağında iş çevresinin olduğu belirlenmiştir. Hemşirelerin, Problem Çözme Envanteri toplam puan ortalamalarının orta düzeyde olduğu tespit edilmiştir $(81,33 \pm 19,91)$. Katılımcıların, eğitim durumlarına göre, Problem Çözme Envanteri'nin aceleci ve kaçıngan yaklaşım alt boyutlarının puan ortalamaları arasındaki fark istatistiksel açıdan anlamlı bulunmuştur $(\mathrm{f}=2,82 ; \mathrm{p}<0,05, \mathrm{f}=3,05 ; \mathrm{p}<0,05)$. Ayrıca, Sağlık Meslek Lisesi mezunu hemşirelerin Problem Çözme Envanteri'nin aceleci ve kaçıngan yaklaşım alt boyutlarının puan ortalamaları, lisansüstü mezunu hemşirelere göre yüksek bulunmuştur. Eğitim durumu problem çözme becerisini önemli derecede etkilemektedir. Hemşirelik eğitimi sürecinde verilen müfredatın güncellenmesi ya da mezuniyet sonras1 eğitimlere devam edilmesi önerilebilir.
\end{abstract}

Anahtar Kelimeler: Acil, Acil hemşireliği, Problem çözme becerisi.

\begin{abstract}
The study was conducted to determine the problem solving skills of nurses working in emergency departments. The study were carried out with 120 nurses, accepted the survey, Cukurova University Faculty of Medicine Balcalı Hospital, Numune Training and Research Hospital in Adana and Yozgat City Hospital, Yozgat Bozok University Health Practice And Research Center nurses working in emergency clinics, between January 2016 and June 2016. In the collection of data was used the personal information form with Problem Solving Inventory. In the evaluation of the data, descriptive statistics and ANOVA test were used. It was determined that $74.27 \%$ of them did not receive training on problem solving and $55.8 \%$ were working environment in the source of the problem. It was found that the mean total score of the nurses in the Problem Solving Inventory was at a moderate level $(81.33 \pm 19.91)$. According to the educational status of the nurses, the difference between the mean scores of the hasty and avoidant approach sub-factors of the Problem Solving Inventory was found to be statistically significant ( $\mathrm{f}=$ $2.82 ; \mathrm{p}<0.05, \mathrm{f}=3.05 ; \mathrm{p}<0.05)$. In addition, the mean scores of the hasty and avoidant approach sub-factors of the Problem Solving Inventory of nurses graduated from Health Vocational High School more higher postgraduate graduate nurses. Educational status significantly affects problem solving skills. İt may be recommended updating the curriculum given in the nursing education process or to continue postgraduate education.
\end{abstract}

Keywords: Emergency, Emergency nursing, Problem Solving skills.

\footnotetext{
Çukurova Üniversitesi Tip Fakültesi Girişimsel Olmayan Araştırmalar Etik Kurulu’ndan etik kurul izni (Etik Kurul:09.01.2016 49/Karar no:12) alınmışttr. 2. Uluslararası 10. Ulusal Türk Cerrahi ve Ameliyathane Hemşireliği Kongresi'nde (02-05 Kasım 2017) poster olarak sunulmuştur. ${ }^{1}$ Öğretim Görevlisi, Özlem ŞAHİN AKBOĞA, Cerrahi Hastalıklar Hemşireliği, Yozgat Bozok Üniversitesi Sağlık Bilimler Fakültesi,
Hemşirelik Bölümü, ozlemsahin.os17@ gmail.com, ORCID: 0000-0002-6767-4195
${ }^{2}$ Prof. Dr. Sevban ARSLAN, Cerrahi Hastalıklar Hemşireliği, Çukurova Üniversitesi Sağlık Bilimler Fakültesi, Hemşirelik Bölümü,
sevbanadana@hotmail.com, ORCID: 0000-0002-8893-9391
}

Geliş Tarihi / Received: 26.12.2020

Kabul Tarihi/Accepted: 01.09.2021 


\section{GİRIȘ}

Kesintisiz hizmet veren acil klinikler, pek çok duruma (çeşitli semptomlar, şikayetler, hastalıklar ve yaralanma gibi) müdahale etmektedir. ${ }^{1}$ Ayrica, klinik durumu acil olan ve acil olmayan her bireyin başvurusu acil klinik yoğunluğunu arttırmaktadır. Yoğunluk, acil bakım hizmetinin yavaşlamasına ve bakım alanın azalmasına neden olmaktadır. ${ }^{2}$ Türkiye 2016 yılı verilerine göre acil kliniklere bir yıldaki başvuru sayısının 110 milyonu geçtiği belirtilmiştir. $^{3}$ Farklı ülkelerde yapılan çalışmalarda, acil kliniklerin kapasitesinin \%50-68'inden fazla çalıştığı bildirilmiştir., $\mathrm{Bu}$ karmaşa, klinik çalışanlarının diğer bireylerle iletişim kurmasını engellemekte ve klinik çalışanlarını gereksiz yere meşgul etmektedir. $^{6,7}$ Acil müdahale edilmesi gereken hastaların ise gereksiz yere beklemesine, yeterli bakım hizmeti alamamasına ve bakım memnuniyetinin azalmasına neden olduğu bildirilmektedir. ${ }^{7}$ Yapılan bir çalışma sonucunda acil kliniklerin yoğunluğunun, hasta bekleme süresini $\% 25$ arttırdığ 1 , bakım kalitesini ve memnuniyet düzeyini azalttığı saptanmıştır. ${ }^{8}$ Acil klinikte, karşılaşılan (ölüme ve hastaların acılarına tanıklık etme, cinsel tacize uğramış bir çocuğa bakıcılık yapma, şiddete tanıklık etme veya tanık olma ve kitlesel yaralanma gibi) olaylar, yaşanan problemi oldukça arttırmaktadır. ${ }^{9}$ Öte yandan, mevcut problemlere yapisal ve ekonomik problemlerin eklenmesi sağlik çalışanlarının işini oldukça zorlaştırmaktadır. ${ }^{2}$ Acil klinikte çalışan sağlık çalışanların çoğunluğunu oluşturan hemşireler, iletişim sürekliliğini sağlama ve etkili bakım verme için karşılaşılan tüm bu problemler ile başedebilmesi beklenmektedir. ${ }^{10}$ Problemleri azaltmak için, etkili triyaj uygulamaları ve eğitimler gibi etkili çözüm yöntemlerini içeren çalışmalar yapılmıştır. ${ }^{11,12} \quad$ Problem çözüm yöntemlerinin temelinde, çalışanların iyi bir problem çözme becerisine (PÇB) sahip olması gerekliliği vurgulanmıştır. ${ }^{13}$ Çünkü, PÇB'si hızlıca problemi tanıma, alternatif çözümler üretme, çözümü uygulama, karar verme, zihinsel ve bilişsel yetenekler, yargılama gücü ve iş ortamında örgütsel davranma gibi pek çok beceriyi ciddi şekilde etkilemektedir. ${ }^{13,14}$ Pek çok becerinin temeli olan PÇB'si, yoğun acil ortamında asla göz ard1 edilmemelidir. ${ }^{13,15}$ Hemşirelerin problem çözme becerisi, klinik alanda en önemli gereksinimidir. ${ }^{16}$ Hemşireler, pek çok problem ile karşılaşılan acil klinikte, bu beceriye daha fazla ihtiyaç duyacaktır. ${ }^{13}$ Literatürde, farklı acil kliniklerde çalışan hemşirelerin PÇB düzeylerinin incelendiği çalışmaya rastlanmamıştır.

$\mathrm{Bu}$ kapsamda araştırma birçok farklı merkezde çalışan acil klinik hemşirelerin PÇB'lerinin incelenmesi amaciyla yapılmıştır.

\section{Araştırma Soruları}

1. Acil klinik hemşirelerinin PÇB'si ne düzeydedir?

2. Acil klinik hemşirelerinin PÇB'sini etkileyen faktörler nelerdir?

\section{MATERYAL VE METOT}

\section{Araştırmanın Türü}

Araştırma, tanımlayıcı-kesitsel olarak gerçekleştirilmiştir.

\section{Araştırmanın Yeri ve Zamanı}

Araştırma, Ocak 2016-Haziran 2016 tarihleri arasında, Adana Çukurova Üniversitesi Tıp Fakültesi Balcalı Hastanesi (40 hemşire) ile Adana Numune Eğitim ve
Araştırma Hastanesi (56 hemşire), Yozgat Bozok Üniversitesi Sağlık Uygulama ve Araştırma Merkezi (12 hemşire) ile Yozgat Şehir Hastanesi'nin (19 hemşire) acil kliniklerinde yürütülmüştür.

\section{Araştırmanın Evreni ve Örneklemi}

Çalışmanın evrenini, belirtilen hastanelerin acil kliniklerinde çalışan toplam 
127 hemşire oluşturmuştur. Örneklem seçimine gidilmeden tüm evrene ulaşılması hedeflenmiştir. Ancak sözel olarak katılmak istemediğini beyan eden 3 hemşire, doğum izninde olan 2 hemşire ve ücretsiz izinde olan 2 hemşire çalışma dışında bırakılmıştır. Araştırmaya katılmayı sözlü ve yazılı olarak beyan eden 120 hemşire ile çalışma yürütülmüştür.

\section{Veri Toplama Araçları ve Verilerin Toplanması}

Araștırmanın verileri "Tanıtıcı Bilgi Formu" ve "Problem Çözme Envanteri (PÇE)" aracılığıyla toplanmıştır.

\section{Tanitıcı bilgi formu}

$\mathrm{Bu}$ form, literatür araştırmasına dayalı olarak hazırlanmıştır. ${ }^{17,18,19,20}$ Formda, acil klinik hemşirelerinin sosyo-demografik bilgileri (yaş, cinsiyet, medeni durum, eğitim durumu, çalışma yılı, haftalık çalışma süresi, mesleği isteyerek seçme durumu) ile PÇB'sini etkilediği düşünülen özellikleri içeren (eğitim alma durumu, PÇB'si açısından kendisini nasıl değerlendirdiği ve en sık çözmek zorunda kaldıkları problem kaynakları) toplam 10 soru yer almaktadır.

\section{Problem çözme envanteri (PÇE)}

$\mathrm{Bu}$ envanter, hemşirelerin PÇB'leri konusunda kendi algılayışlarını belirlemek için tasarlanmış olup, Heppner ve Peterson tarafından 1982 yılında geliştirilmiştir. 1993 yılında ise Türkçe geçerlilik güvenirliği Şahin ve arkadaşları tarafindan yapılmıştır. ${ }^{21,22}$ Envanter, altı alt boyut (aceleci yaklaşım (AY) ile ilgili maddeler; $13,14,15,17,21,25,26,30$ ve 32), düşünen yaklaşım (DY) (8, 20, 31, 33 ve 35), kaçıngan yaklaşım $(\mathrm{KY})(1,2,3,4$ ve 11$)$, değerlendirici yaklaşım (DĞY) $(6,7$ ve 8), kendine güvenen yaklaşım (KGY) $(5,23,24$, 27,28 ve 34) ve planlı yaklaşım (PY) (10, 12,16 ve 19)) olmak üzere toplam 35 sorudan oluşmaktadır. 35 sorudan 3'ü $(9,22$ ve 29. sorular) puanlama dişı bırakılıp, 32 soru üzerinden puanlanmaktadır. Kalan her bir soruya 1-6 ("1=her zaman böyle davranırım", "2=çoğunlukla böyle davranırım", " $3=$ sık sık böyle davranırım", "4=arada sırada böyle davranırım", " $5=$ ender olarak böyle davranırım" ve " $6=$ hiçbir zaman böyle davranmam") arasında puanlanmaktadır. Envanterden alınabilecek puan 32 ila 192 arasıdır. Toplam puan yüksekse, bireyin PÇB'si konusunda kendini yetersiz algıladığ konusunda kendini iyi algıladığı anlamına gelmektedir. Ölçeğin orijinalinin güvenilirlik çalışmasında Cronbach alfa güvenilirlik katsayısı 0,90'dur. ${ }^{21} \mathrm{Bu}$ çalışmada ise Cronbach alfa güvenilirlik katsayısı $0,85^{\prime}$ 'tir (Tablo 1).

Tablo 1. Problem Çözme Envanteri (PÇE) Tüm Alt Boyutların Güvenilirlik Değerlendirmesi

\begin{tabular}{lcr}
\hline & $\begin{array}{c}\text { Cronbach's } \\
\text { Alpha }\end{array}$ & $\begin{array}{c}\text { Madde } \\
\text { sayısı }\end{array}$ \\
\hline AY &, 71 & 9 \\
DY &, 78 & 5 \\
KY &, 50 & 4 \\
DĞY &, 79 & 3 \\
KDY &, 69 & 6 \\
PY &, 73 & 4 \\
PÇE toplam puan &, 85 & 32 \\
\hline AY: Aceleci yaklaşım, DY: Düşünen yaklaşım, KY: \\
Kaçıngan yaklaşım, DĞY: Değerlendirici yaklaşım, \\
KGY: Kendine güvenen yaklaşım, PY: Planlı yaklaşım
\end{tabular}

\section{Verilerin Toplanması}

Veri toplama formlar1, 01.02.201601.07.2016 tarihleri arasında, araştırmacı tarafından acil kliniklerde çalışan hemşirelere dağıtılmıştır. Araştırmanın amacı, içeriği ve kapsamı konusunda bilgi verildikten sonra, uygun zaman diliminde doldurmaları istenmiştir. Tamamlanan formlar, araştırmacı tarafından geri toplanmıştır.

\section{Verilerin Değerlendirilmesi}

Verilerin kodlanmas1 ve değerlendirilmesi, bilgisayar ortamında bir istatistik paketi aracılığıla (IBM SPSS for Windows 21.0) yapıldı. Çalışma verileri değerlendirilirken tanımlayıcı istatistiksel yöntemler (Frekans, Yüzde, Ortalama, Standart sapma), normal dağılımın incelenmesi için Kolmogorov - Smirnov dağılım testi kullanılmıştır. Niceliksel verilerin karşılaştırılmasında ikiden fazla grup durumunda, normal dağılım gösteren 
parametrelerin gruplar aras1 karşılaştırmalarında tek yönlü (oneway) varyans analizi, alt boyutlar arasındaki ilişkiyi incelemek için korelasyon analizi ve gruplar arasındaki farkın anlamlılığını belirlemek için post-hoc analizi kullanılmıştır. Sonuçlar \%95 güven aralığında, $\quad \mathrm{p}<0,05$ anlamlılık düzeyinde değerlendirilmiştir.

\section{Araştırmanın Etik Yönü}

Araştırma için; katılımcılardan Bilgilendirilmiş Gönüllü Onam Formu, Çukurova Üniversitesi Tıp Fakültesi
Girişimsel Olmayan Araştırmalar Etik Kurulu'ndan etik kurul izni (Etik Kurul:09.01.2016 49/Karar no:12) ve ilgili kurumlardan kurum izni (Kurum İzni: 45868485-399 E.35546, 69937107-799, 78535428-106.01 E. 3529, 16142545. 302. 14.01/895 sayılı izin) alınmıştır.

\section{Araştırmanın Kısıtlılıkları}

Sonuçlar sadece araştırmanın yürütüldüğü hastanelerde çalışan acil klinik hemşireleri ile sınırlıdır. Tüm acil klinik çalışan hemşirelerine genellenemez.

\section{BULGULAR VE TARTIŞMA}

Acil klinik hemşirelerinin yarısına yakının, 26-35 yaş aralığında (\%42,50), lisans mezunu $(\% 49,20)$ ve yarısindan fazlasının kadın $(\% 66,67)$ ve evli $(\% 53,33)$ olduğu saptanmıştır. Ayrıca, yarısından fazlası ortalama 40 saat çalıştığı $(\% 51,67)$, problem çözmede kendini başarılı bulduğu $(\% 53,33)$ ve problem kaynağ 1 olarak iş çevresini gördüğü $(\% 55,84)$ belirlenmiştir. Büyük bir oranın ise çalışma yılının 10 yıl ve altında olduğu $(\% 72,50)$, mesleğini isteyerek seçtiği $(\% 70,80)$ ve PÇB'sini geliştirecek herhangi bir eğitim almadığ 1 (\%74,27) görülmüştür (Tablo 2.).

Tablo 2. Hemşirelerin Tanıtıcı Özelliklerinin Dağılımı

\begin{tabular}{lrr}
\hline $\begin{array}{l}\text { Tanıtıcı } \\
\text { Özellikler }\end{array}$ & Sayı & \multicolumn{1}{c}{$\%$} \\
\hline Yaş & 47 & 39,17 \\
$18-25$ arası & 51 & 42,50 \\
$26-35$ arası & 17 & 14,17 \\
$36-45$ arası & 5 & 4,16 \\
$46-55$ arası & & \\
\hline Cinsiyet & 80 & 66,67 \\
Kadın & 40 & 33,33 \\
Erkek & & \\
\hline Medeni durum & 64 & 53,33 \\
Evli & 56 & 46,77 \\
Bekar & & \\
\hline Eğitim Durumu & 36 & 30,00 \\
SML & 19 & 15,80 \\
Önlisans & 59 & 59,20 \\
Lisans & 6 & \\
Lisans üstü & & \\
\hline Çalışma süresi & 87 & \\
10 yıl ve altı & & \\
& &
\end{tabular}

Tablo 2. (Devamı) Hemşirelerin Tanıtıcı Özelliklerinin Dağılımı

\begin{tabular}{lcr}
\hline $11-20$ yıl & 25 & 20,83 \\
21 yıl ve üzeri & 8 & 6,67 \\
\hline PÇ İle İlgili Eğitim Alma Durumu & \\
Evet & 31 & 25,83 \\
Hayır & 89 & 74,27 \\
\hline Mesleği İsteme Durumu & & \\
Evet & 85 & 70,80 \\
Hayır & 35 & 29,20 \\
\hline Haftalık Çalışma Süresi & & \\
40 st. altı & 11 & 9,16 \\
40 st. & 62 & 51,67 \\
40 st. üzeri & 47 & 39,17 \\
\hline PÇB Kendini Algılama Durumu & \\
Başarısız & 4 & 3,33 \\
Kismen Başarılı & 34 & 28,33 \\
Başarılı & 64 & 53,34 \\
Çok başarılı & 18 & 15,00 \\
\hline Problem Kaynağı Düşünme Durumu \\
İş çevrem \\
Ailem & 67 & \\
Sosyal çevre & 22 & 55,84 \\
Cevap yok & 21 & 18,33 \\
\hline PÇ: Problem Çözme, St: Saat, & PÇB: Problem Çözme \\
Becerisi & & \\
& &
\end{tabular}

Acil klinik hemşirelerinin PÇE'nin alt boyutlarının (aceleci, düşünen, kaçıngan, değerlendirici, kendine güvenli ve planlı yaklaşım) puan ortalamaları sırası ile $30,67 \pm 8,19, \quad 13,14 \pm 5,46, \quad 10,96 \pm 4,36$, $7,92 \pm 4,09,16,80 \pm 5,96$ ve $10,567 \pm 4,47^{\prime}$ 'dir. En düşük puan $7,92 \pm 4,09$ ile değerlendirici yaklaşım, en yüksek puan $30,67 \pm 8,19$ ile aceleci yaklaşımdır. PÇE toplam puan ortalamas1 ise orta düzeydedir $(81,33 \pm 19,91)$ (Tablo 3). 
Tablo 3. Hemşirelerin Problem Çözme Envanteri (PÇE) ve Alt Boyut Puan Ortalamalarının Dağılımı

\begin{tabular}{|c|c|c|}
\hline \multirow[b]{2}{*}{$\begin{array}{l}\text { PÇE alt } \\
\text { boyut }\end{array}$} & \multicolumn{2}{|c|}{ Puanlar } \\
\hline & Ort \pm Ss. & Max. \\
\hline AY & $30,67 \pm 8,19$ & $10-50$ \\
\hline DY & $13,14 \pm 5,46$ & $5-30$ \\
\hline KY & $10,96 \pm 4,36$ & $4-22$ \\
\hline DĞY & $7,92 \pm 4,09$ & $3-18$ \\
\hline KGY & $16,80 \pm 5,96$ & $6-32$ \\
\hline PY & $10,56 \pm 4,47$ & $4-24$ \\
\hline Toplam & $81,33 \pm 19,91$ & $34-133$ \\
\hline $\begin{array}{l}\text { AY: Acele } \\
\text { Kaçıngan } \\
\text { KGY: Ke } \\
\text { yaklaşım, } \\
\text { Ortalama, }\end{array}$ & $\begin{array}{l}\text { aklaşım, DY: Düşüne } \\
\text { laşım, DGY: Değerle } \\
\text { le güvenen yaklaşı } \\
\text { n.: En az, Max.: } \\
\text { Standart Sapma, } \alpha: C h\end{array}$ & $\begin{array}{l}\text { im, KY: } \\
\text { aklaşım, } \\
\text { Planlı } \\
\text { Ort.: } \\
\text { alfa }\end{array}$ \\
\hline
\end{tabular}

Eğitim durumu ile aceleci ve kaçıngan yaklaşım alt boyutlar arasında istatistiksel açıdan anlamlı farklılık bulunmuştur ( $\mathrm{f}=2,82$, $\mathrm{p}=0,04<0.05 ; \mathrm{f}=3,05, \mathrm{p}=0,03<0.05)$. Farkin kaynağını anlamak amaciyla yapılan tamamlayıc1 post-hoc analizde, aceleci yaklaşım alt faktör puanı, eğitim durumu SML ve lisans olan hemşirelerin $(31,72 \pm 8,14,31,78 \pm 7,52)$, eğitim durumu lisansüstü olan hemşirelere $(25,50 \pm 10,85)$ göre yüksek bulunmuştur $(\mathrm{f}=2,82 ; \mathrm{p}<0.05)$ (Tablo 5). Ayrıca, kaçıngan yaklaşım alt boyut puanının, eğitim durumu SML ve lisans mezunu olan hemşirelerin $(12,05 \pm 4,99, \quad 11,00 \pm 3,92)$ eğitim durumu lisansüstü olan hemşirelere göre $(6,66 \pm 2,25)$ yüksek olduğu saptanmıştır $(\mathrm{f}=3,05 ; \mathrm{p}<0.05)$ (Tablo 4). Diğer özellikler (yaş, cinsiyet, medeni durum, çalışma yılı, haftalık çalışma süresi, mesleği isteyerek seçme durumu, problem çözme ile ilgili eğitim alma durumu, PÇB'si açısından kendisini nasıl değerlendirdiği ve en sık çözmek zorunda kaldıkları problem kaynakları) ile PÇE'nin alt faktörleri arasında anlamlı ilişki olmadığ 1 belirlenmiştir.
Tablo 4. Acil Klinik Hemşirelerinin Eğitim Durumu ile Problem Çözme Envanteri (PÇE) Alt Boyut Puan Ortalamalarının Karşılaştırılması

\begin{tabular}{|c|c|c|c|c|}
\hline $\begin{array}{l}\text { PÇE } \\
\text { Alt } \\
\text { Boyut }\end{array}$ & $\begin{array}{l}\text { Eğitim } \\
\text { durumu }\end{array}$ & Ort \pm Ss. & Test & $\mathbf{p}$ \\
\hline \multirow{4}{*}{ AY } & SML & $31,72 \pm 8,14$ & \multirow{4}{*}{$\begin{array}{r}\mathrm{f}: \\
2,825\end{array}$} & \multirow{4}{*}{$\begin{array}{r}0,042 \\
*\end{array}$} \\
\hline & Ön lisans & $26,89 \pm 8,31$ & & \\
\hline & Lisans & $31,78 \pm 7,52$ & & \\
\hline & $\begin{array}{l}\text { Lisans } \\
\text { üstü }\end{array}$ & $25,50 \pm 10,85$ & & \\
\hline \multirow{4}{*}{ DY } & SML & $13,27 \pm 5,65$ & \multirow{4}{*}{$\begin{array}{r}\mathrm{f}: \\
0,966\end{array}$} & \multirow{4}{*}{0,412} \\
\hline & Ön lisans & $12,00 \pm 5,19$ & & \\
\hline & Lisans & $13,10 \pm 5,05$ & & \\
\hline & $\begin{array}{l}\text { Lisans } \\
\text { üstü }\end{array}$ & $16,33 \pm 8,80$ & & \\
\hline \multirow{4}{*}{ KY } & SML & $12,05 \pm 4,99$ & \multirow{4}{*}{$\begin{array}{r}\mathrm{f} \\
: 3,056\end{array}$} & \multirow{4}{*}{$\begin{array}{r}\mathbf{0 , 0 3 1} \\
*\end{array}$} \\
\hline & Ön lisans & $10,15 \pm 4,14$ & & \\
\hline & Lisans & $11,00 \pm 3,92$ & & \\
\hline & $\begin{array}{l}\text { Lisans } \\
\text { üstü }\end{array}$ & $6,66 \pm 2,25$ & & \\
\hline \multirow{4}{*}{ DĞY } & SML & $8,91 \pm 4,10$ & \multirow{4}{*}{$\begin{array}{r}\mathrm{f}: \\
1,009\end{array}$} & \multirow{4}{*}{0,392} \\
\hline & Ön lisans & $7,52 \pm 4,50$ & & \\
\hline & Lisans & $7,49 \pm 3,74$ & & \\
\hline & $\begin{array}{l}\text { Lisans } \\
\text { üstü }\end{array}$ & $7,50 \pm 5,82$ & & \\
\hline \multirow{4}{*}{ KGY } & SML & $17,66 \pm 6,20$ & \multirow{4}{*}{$\begin{array}{r}\mathrm{f}: \\
0,652\end{array}$} & \multirow{4}{*}{0,583} \\
\hline & Ön lisans & $15,68 \pm 5,79$ & & \\
\hline & Lisans & $16,81 \pm 5,69$ & & \\
\hline & Lisans üstü & $15,00 \pm 8,09$ & & \\
\hline \multirow{4}{*}{ PY } & SML & $10,69 \pm 4,65$ & \multirow{4}{*}{$\begin{array}{r}\mathrm{f}: \\
0,204\end{array}$} & \multirow{4}{*}{0,894} \\
\hline & Ön lisans & $10,52 \pm 4,27$ & & \\
\hline & Lisans & $10,37 \pm 4,19$ & & \\
\hline & $\begin{array}{l}\text { Lisans } \\
\text { üstü }\end{array}$ & $11,83 \pm 7,19$ & & \\
\hline \multirow{4}{*}{ Toplam } & SML & $84,92 \pm 20,15$ & \multirow{4}{*}{$\begin{array}{r}\mathrm{f}: \\
1,567\end{array}$} & \multirow{4}{*}{0,201} \\
\hline & Ön lisans & $73,82 \pm 19,81$ & & \\
\hline & Lisans & $82,17 \pm 18,71$ & & \\
\hline & $\begin{array}{l}\text { Lisans } \\
\text { üstü }\end{array}$ & $74,64 \pm 27,22$ & & \\
\hline
\end{tabular}

SML: Săglık Meslek Lisesi, AY: Aceleci yaklaşım, DY: Düşünen yaklaşım, KY: Kaçıngan yaklaşım, DĞY: Değerlendirici yaklaşım, KGY: Kendine güvenen yaklaşım, PY: Planlı yaklaşım Ort.: Ortalama, SS: Standart Sapma, $f$ : ANOVA Testi *p<0,05

Araştırma kapsamında incelenen PÇE alt boyutlar arasındaki korelasyon katsayıları arasındaki ilişki incelendiğinde; PÇE "aceleci yaklaşım" ile "kaçıngan yaklaşım" arasında pozitif yönde orta düzeyde ilişki, 
"düşünen yaklaşım" ile "değerlendirici ve kendine güvenli yaklaşım arasında pozitif yönde orta düzeyde ilişki , "planlı yaklaşım" arasında pozitif yönde yüksek düzeyde ilişki, "kaçıngan yaklaşım" ile "kendine güvenli yaklaşım" arasında pozitif yönde düşük düzeyde ilişki, "değerlendirici yaklaşım” ile "kendine güvenli ve planlı yaklaşım" arasında pozitif yönde orta düzeyde ilişki, "kendine güvenli yaklaşım" ile "planlı yaklaşım" arasında pozitif yönde orta düzeyde ilişki olduğu saptanmıştır $(\mathrm{p}=.000$; $\mathrm{p}<0.05$ ) (Tablo 5). Genel olarak, olumlu yaklaşımlar ile olumsuz, olumsuz yaklaşımlar ile olumlu yaklaşımlar arasında anlamlı ilişki olmadığı bulunmuştur.

Tablo 5. Problem Çözme Envanteri (PÇE) Alt Boyutlar Arasındaki Korelasyon Katsayıları

\begin{tabular}{|c|c|c|c|c|c|c|}
\hline $\begin{array}{l}\text { PÇE } \\
\text { Alt } \\
\text { Boyut }\end{array}$ & & DY & KY & DĞY & KGY & PY \\
\hline \multirow[b]{2}{*}{ AY } & \multirow{2}{*}{$\begin{array}{l}\mathrm{r} \\
\mathrm{p}\end{array}$} & $-0,03$ & \multirow{2}{*}{$\begin{array}{r}0,05 \\
\mathbf{0 , 0 0} \\
*\end{array}$} & $-0,15$ & 0,14 & $-0,03$ \\
\hline & & 0,73 & & & & 0,73 \\
\hline \multirow[b]{2}{*}{ DY } & \multirow{2}{*}{\multicolumn{2}{|c|}{$\begin{array}{l}\mathrm{r} \\
\mathrm{p}\end{array}$}} & 0,09 & \multirow{2}{*}{$\begin{array}{r}0,63 \\
\mathbf{0 , 0 0} \\
*\end{array}$} & \multirow{2}{*}{$\begin{array}{r}0,68 \\
\mathbf{0 , 0 0 *}\end{array}$} & \multirow{2}{*}{$\begin{array}{r}0,75 \\
\mathbf{0 , 0 0 *}\end{array}$} \\
\hline & & & 0,28 & & & \\
\hline \multirow{2}{*}{ KY } & \multicolumn{2}{|l|}{$\mathrm{r}$} & & 0,06 & 0,19 & \multirow{2}{*}{$\begin{array}{l}0,09 \\
0,31\end{array}$} \\
\hline & \multicolumn{2}{|l|}{$\mathrm{p}$} & & 0,49 & $\mathbf{0 , 0 3} *$ & \\
\hline \multirow{2}{*}{ DĞY } & \multicolumn{2}{|l|}{$\mathrm{r}$} & & & 0,57 & 0,70 \\
\hline & \multicolumn{2}{|l|}{$\mathrm{p}$} & & & $\mathbf{0 , 0 0 *}$ & $\mathbf{0 , 0 0 *}$ \\
\hline \multirow{2}{*}{ KGY } & \multirow{2}{*}{\multicolumn{2}{|c|}{$\begin{array}{l}\mathrm{r} \\
\mathrm{p}\end{array}$}} & & & & 0,70 \\
\hline & & & & & & $\mathbf{0 , 0 0 *}$ \\
\hline \multicolumn{7}{|c|}{$\begin{array}{l}\text { AY: Aceleci yaklaşım, DY: Düşünen yaklaşım, KY: } \\
\text { Kaçıngan yaklaşım, DGY: Değerlendirici yaklaşım, } \\
\text { KGY: Kendine güvenen yaklaşım, PY: Planlı } \\
\text { yaklaşım, } r: \text { Korelasyon Analizi } * p<0,05\end{array}$} \\
\hline
\end{tabular}

Hemşirelerin yaklaşık yarısı 26-35 yaş aralığında, lisans mezunu, çoğunluğunun ise çalışma süresi 10 yılın altındadır. Yapılan farklı iki çalışmada da araştırmaya katılan hemşirelerin genellikle genç yaşta olduğu, eğitim durumu oranlarının farklı olduğu ve kısa süreli çalıştığı görülmektedir. ${ }^{17,18} \mathrm{Bu}$ bulgular genel olarak, diğer çalışmalarla benzerdir.

Çalışmada, acil klinik hemşireleri, PÇE alt boyutlarından değerlendirici ve planlı yaklaşımdan en düşük puanı almıştır $(7,92 \pm 4,09,10,56 \pm 4,47)$. Bu sonuç, acil klinik hemşirelerinin problemi çözerken olumlu yaklaşımlarda kendini yeterli algıladığının başlıca göstergesidir. Bahar ve arkadaşlarının (2019) çalışmasında da, hemşireler, PÇE alt boyutlarından değerlendirici ve planlı yaklaşımdan en düşük puanı almıştır $(8,03 \pm 3,23$, 12,22 $\pm 2,93) \cdot{ }^{17}$ Çalışmamız diğer çalışma sonuçları ile paraleldir. Acil klinik hemşireleri, hasta, hasta yakınları ve çalışma arkadaşlarının düşüncelerini değerlendirebilme becerisine sahiptir. $\mathrm{Bu}$ beceri, acil klinik yoğunluğunun yarattığ1 sorunların yönetilmesinde de oldukça kolaylık sağlayacaktır. ${ }^{19}$ Hemşireler olumsuz yaklaşımlardan (aceleci ve kaçıngan) kaçınmakta, olumlu yaklaşımlara (değerlendirici, planlı, düşünen gibi) daha fazla yönelmektedir. Acil kliniğin yoğunluğunun, çalışanları olumsuz yaklaşımlara yöneltmediğini söyleyebiliriz.

Çalışmada, hemşirelerin PÇE puan ortalamasinın orta düzeyde olduğu belirlenmiştir $(81,33 \pm 19,91)$. Yapılan pek çok çalışmada da PÇE puan ortalamasının orta düzeyde olduğu görülmüştür. ${ }^{20,23-25}$ Hemşirelerin, orta düzeyde PÇB'lerinin kaliteli bakım hizmetinin verilebilmesi ve hızlı problem çözüm önerilerinin üretilebilmesi için geliştirilmesi gerekmektedir.

Çalışmamızda eğitim durum dışındaki diğer tanıtıcı özellikler ile hemşirelerin PÇB düzeyleri arasında bir farklılık bulunamadı. Literatürde PÇB'si ile diğer tanıtıcı özellikler (yaş, cinsiyet, medeni durum, çalışma yıl1, haftalık çalışma süresi, mesleği isteyerek seçme durumu, PÇB'sini etkileyen eğitim alma durumu, PÇB'si açısından kendisini nasıl değerlendirdiği ve en s1k çözmek zorunda kaldıkları problem kaynakları, problem çözme ile ilgili eğitim alma durumu, problem çözme yeteneği açısından kendisini nasıl değerlendirdiği ve en s1k çözmek zorunda kaldıkları problem kaynakları) arasındaki ilișkilerin incelendiği çalışmalarda benzer ve farklı bulgulara rastlanmıștır. ${ }^{17,18 \text {, }}$ 20, 23-28 Örneğin, yaş ve PÇE puan ortalamaları arasında farklı üç çalışmada da istatiksel anlamlı ilişki saptanmamıştır. ${ }^{18,23,28}$ Cinsiyet ve PÇE puan ortalamaları arasında ise farklı 
üç çalışmada istatiksel anlamlı ilişki saptanmazken ${ }^{24-26}$ bir çalışmada, PÇE alt boyutu olan kişisel kontrol arasında istatiksel anlamlı ilişki saptanmıştır. ${ }^{18}$ Medeni durum ile PÇE puan ortalamaları arasında üç çalışmada anlamlı farklılık saptanırken, ${ }^{24,26,28}$ iki çalışmada anlamlılık saptanmamıştır. ${ }^{18,25}$ Çalışma yılı ve PÇE toplam puan ortalamaları arasında iki çalışmada anlamlılık saptanırken, ${ }^{25,26}$ diğer çalışmalarda anlamlılık saptanmamıștır. ${ }^{18,23-25,27}$ Hemşirelerin mesleği sevme durumları ile PÇE toplam puan ortalamaları arasında anlamlı ilişki saptanmamıştır. ${ }^{26}$ Çalışmamızda hemşirelerin büyük bir çoğunluğu iş çevresi kaynaklı problem yaşadığını belirtmiştir $(\% 55,84)$. Bu konuda hemşirelerin iş kaynaklı problem nedeni daha detaylı araştırılmalı ve probleme yönelik çözüm önerileri sunulmalıdır. İş çevresini problem kaynağı olarak görmek yerine, Çınar ve arkadaşları (2010) multidisipliner ekip işbirliği içinde çalışmanın, sağlık çalışanlarının PÇB'sini arttırdığını ileri sürmüştür. ${ }^{29}$ PÇB'sini etkileyen başka bir faktör de, kişisel farkındalıktır. ${ }^{30}$ Yapılan bir çalışmada, kişisel farkındalığın PÇE puan ortalamalarında istatiksel olarak anlaml farklilik saptanmamıştır. ${ }^{20}$ PÇB'sini etkileyen bu faktörlerin, etkisini netleştirmek için, daha fazla çalışılmalıdır.

PÇB'si sonradan da öğrenilebilen ve geliştirilebilen bir beceridir. ${ }^{20}$ Acil ortamında, en iyi ve uygun kararı almak, problem çözme ve karar verme becerilerini geliştirmek için iş başında eğitim alınmalıdır. $^{13}$ Oysaki, çalışmamızda, hemşirelerin mezuniyet sonrası problem çözmeye yönelik eğitim alma durum oranının oldukça düşük olduğu göze çarpmaktadır $(\% 25,83)$. Yapılan çalışmalarda da hemşirelerin büyük oranının PÇB'sini artırmaya yönelik eğitim almadığı saptanmıştır. ${ }^{18,25,26}$ Oysaki hemşirelik mesleği süresince problem çözme eğitimini alma durumu, PÇE toplam puan ortalamalarını etkilemektedir. ${ }^{18,25}$ Eğitim düzeyi arttıkça, bireydeki bu becerinin artması beklenmektedir. ${ }^{31}$ Çalışmamız da bu düşünceyi destekler nitelikte olup, özellikle eğitim durumu lisans ve lisansüstü düzeyde olan hemşirelerin problem çözmede yetenekli oldukları, hatta olumsuz yaklaşımlarla daha iyi baş edebildiği saptanmıştır. Heidari ve Shahbazi (2016)'nin çalışmasında acil klinik çalışanlarında, önlisans mezunlarının diğer mezunlara göre PÇB'lerinin zayıf olduğu belirtirken, Yıldırım ve Bağsürer (2019) ise çalışmasında eğitim düzeyi arttıkça, bireyin problem ile başetme ve kontrolü sürdürme becerisinin arttığı saptanmıştır. ${ }^{13,18}$ Fakat, Erkuş ve Bahçecik'in çalışmasında (2015) ise SML mezunu yönetici hemşirelerin, lisans mezunu hemşirelerden PÇE genel puanının daha düşük olduğu yani problem çözmede kendilerini daha başarılı algıladıkları saptanmıştır. $^{23}$ Birçok çalışmada ise PÇB'lerini eğitim durumu etkilemediği belirtilmiştir. ${ }^{20,24,27}$ Çalışmalarda bu şekilde farklılık görülmesinin nedeni, eğitim sistemindeki farkl1lıklar, eğitim sisteminin içerisinde farklı sosyo-kültürel çevreden gelen bireylerin olmas1 sayılabilir. Hemşirelik eğitimi ve hemşirelerin mesleki süreçte PÇB'lerini etkileyen diğer faktörler (problem ile karşılaşma sıklığı, sosyokültürel yaşam tarzı ve sosyal destek varlığı gibi) araştırılmalıdır.

Çalışmamızdaki PÇE alt boyutlarının birbirleri ile olan ilişkisi incelendiğinde ise olumlu yaklaşımlar ile olumlu, olumsuz yaklaşımlar ile olumsuz yaklaşımlar arasında beklendik yönde ve anlamlı ilişki olduğu saptanmıştır. PÇE alt boyutlarının birbirleri ile olan ilişkisi incelendiği çalışmaya rastlanmamıştır.

\section{SONUÇ VE ÖNERILLER}

Çalışmada acil kliniklerde çalışan hemşirelerin PÇB'lerinin orta düzeyde olduğu saptanmıştır. Acil klinik hemşiresinin temel amacı, acil servisin doğası gereği hızlı ve acil durumlar karşısında hızlı bir problem çözme süreci gerçekleştirmesi ve yaşadığ 1 problemler karşısında bakım kalitesini korumaktır. PÇB'si yükssek olan bireyler, 
yaşadığı problemleri daha rahat çözümleyecektir. Anahtar öneri, problem ile etkili başedebilmek için, temelde yer alan PÇB'sinin geliştirilmesidir. Hemşireler, buna yönelik kişisel gelişim eğitimleri alabilir. Acil klinikte yaşanan problemleri azaltmak amaciyla hemşireler, topluma acil durum kavramını anlatma, acil klinikte yönlendirme, bilgilendirme, danışmalık verme rollerini etkin kullanmalıdır.

Ayrıca PÇB'sini etkileyen en önemli faktör eğitim durumudur. Üniversite eğitimi, bireylerin kişisel özelliklerin belirginleştiği ve becerilerin geliştiği dönemdir. Bakım hizmeti veren hemşirelerin, üniversite eğitimini tamamlaması önerilebilir. Üniversite eğitiminde müfredatın güçlendirilmesi önerilebilir. Ayrıca acil klinik hemşirelerinin PÇB'leri etkileyen faktörlerin tanımlanmasında daha kapsamlı araştırmalar ve analizler yapılması literatüre farklılık sağlayacaktır. Yeni faktörlerin belirlenmesi ve sorunların çözümlenmesi becerinin olumlu yönünü güçlendirecektir.

\section{KAYNAKLAR}

1. Zimmermann, M, Brokmann, J.C, Gräff, I, Kumle, B, Wilke, P. and Gries, A. (2016). "Emergency Departments--2016 Update". Anaesthesist, 65 (4), 243-249.

2. Bearden, M.B, Brown, T, Kirksey, K.M, Dansby, M. and Hilliard, M. (2008). "Easing The Chaos in Emergency Departments: İmplementation of the 'Ask Your Nurse' Teletriage Program”. J Emerg Nurs, 34 (3), 221-224.

3. Türkiye İstatistik Kurumu. (2016). Erişim adresi: https://rapor.saglik.gov.tr/istatistik/rapor/ (Erişim tarihi: 23.04.2020).

4. Burns, T.R. (2017). "Contributing Factors of Frequent Use of The Emergency Department: A synthesis”. Int Emerg Nurs, 35, 51-55.

5. Van der Linden, V, Reijnen, R, Derlet, R.W, Lindeboom, R, Van der Linden, N, Lucas, C. and Richards, J.R. (2013). "Emergency Department Crowding in The Netherlands: Managers' Experiences". International Journal of Emergency Medicine, 6 (1), 41.

6. Pun, J.K, Chan, E.A, Murray, K.A, Slade, D, Matthiessen. and C.M. (2017). "Complexities of Emergency Communication: Clinicians' Perceptions of Communication Challenges in A Trilingual Emergency Department". J Clin Nurs, 26 (21-22), 3396-3407.

7. Carlson, K. (2016). "Crowding in The Emergency Department”. J Emerg Nurs, 42 (2), 97-98.

8. Hing, E, and Bhuiya, F. (2020). "Wait Time for Treatment in hospital Emergency Departments". Erişim adresi: http://www.cdc.gov/nchs/data/databriefs/db102. (Erişim tarihi: 23.04.2020)

9. Isa, K.Q, Ibrahim, M.A, Abdul-Manan, H.H, Mohd-Salleh, Z.H, Abdul-Mumin, K.H. and Rahman, H.A. (2019). "Strategies Used to Cope With Stress by Emergency and Critical Care Nurses". Br J Nurs, 10, 28 (1), 38-42.

10. Brysiewicz, P. and Emmamally, W. (2017). "Focusing on Families in The Emergency Department". Int Emerg Nurs, 30, $1-2$.

11. Kumar, A, Lakshminarayanan, D, Joshi, N, Vaid, S, Bhoi, S. and Deorari, A. (2019). "Triaging The Triage: Reducing Waiting Time to Triage in The Emergency Department at A Tertiary Care Hospital in New Delhi, India”. Emerg Med J, 36, 558-563.

12. van der Linden, M.C, Meester, B.E. and Van der Linden, N. (2016). "Emergency Department Crowding Affects Triage Processes". Int Emerg Nurs, 29, 27-31.
13. Heidari, M. and Shahbazi, S. (2016). "Effect of Training Problem-Solving Skill on Decision-Making and Critical Thinking of Personnel at Medical Emergencies". Int J Crit Illn Inj Sci, 6 (4), 182-187.

14. Franklin, A, Liu, Y, Li, Z, Nguyen, V, Johnson, T.R. and Robinson, D. (2011). "Opportunistic Decision Making and Complexity in Emergency Care". J Biomed Inform, 44, 469476.

15. Heidari, M, Shahbazi, S. and Derris, F. (2013). "The Effect of Problem Solving Training on Decision Making Skill in Emergency Medicine Students". J Health Promot Manage, 2, 25-31.

16. Abdellah, F.G. (1957). "Methods of Identifying Covert Aspects of Nursing Problems A Key to Improved Clinical Teaching". Nursing Research, 6 (1), 4-23.

17. Bahar, Z, Gördes, N, Fındık, M, Özdilek, S, Ercan, B. ve Ulukaya, T. (2019). "Özel Bir Hastanede Çalışan Hemşirelerin Problem Çözme Becerileri”. Halk Sağlığı Hemşireliği Dergisi, $1(2), 3-14$

18. Yıldırım, B. ve Bağsürer, N. (2019). "Bir Üniversite Hastanesinde Çalışan Hemşirelerin Problem Çözme Süreçlerinin İncelenmesi”. Ortadoğu Tıp Dergisi, 1, 27-33.

19. Yıldırım, A. ve Taşçı, S. (2013). "Hemşirelikte Eleştirel Düşünmenin Klinik Karar Vermeye Etkisi”. Balıkesir Sağlık Bilimleri Dergisi, (2) 3, 187-191.

20. Başar, G, Akın, S. ve Durna, Z. (2015). "Hemşirelerde ve Hemşirelik Öğrencilerinde Problem Çözme ve İletişim Becerilerinin Değerlendirilmesi”. Gümüşhane Üniversitesi Sağlık Bilimleri Dergisi, 4 (1), 125-147.

21. Heppner, P.P. and Petersen, C.H. (1982). "The Development and İmplications of A Personal Problem Solving İnventory.” J Couns Psychol, 29, 66-75.

22. Şahin, N, Şahin, H.N. and Heppner, P. (1993). "Psychometric Properties of The Problem Solving Inventory". Cognitive Therapy and research, 17 (4), 379-396.

23. Erkuş, B. ve Bahçecik, N. (2015). “Özel Hastanelerde Çalışan Yönetici Hemşirelerin ve Hemşirelerin Eleştirel Düşünme Düzeyi ve Problem Çözme Becerileri." Clinical and Experimental Health Sciences, 5 (1), 1-9.

24. Aydınöz, Ö, Özer Küçük, E. ve Gönderen Çakmak, H.S. (2020). "Hemşirelerin Problem Çözme Beceri Düzeyleri ve Etkileyen Faktörler: Bir Eğitim ve Araştırma Hastanesi Örneği”. BÜ Hemşirelik Dergisi, 2 (1), 9-16. 
25. Çelenk, O. ve Topoyan, M. (2017). "Bir Üniversite Hastanesinde Görevli Hemşirelerin Problem Çözme Beceri Düzeylerinin İncelenmesi”. Dokuz Eylül Üniversitesi Hemşirelik Fakültesi Elektronik Dergisi, 10 (4), 251-259.

26. Yılmaz Koçak, M. ve Büyükyılmaz, F. (2019). "Hemşirelerin Öz-yeterlilik Algıları ile Problem Çözme Becerilerinin İncelenmesi". Journal of Academic Research in Nursing, 5 (3), 169-177.

27. Erzincanlı, S. ve Zaybak, A. (2015). "Hemşirelerde Eleştirel Düşünme Eğilimi ve Problem Çözme Becerileri Arasındaki İlişki”. Uluslararası Hakemli Hemşirelik Araştırmaları Derg, 2 (3), 26-38.

28. Karakurt, N. ve Ekinci, M. (2015). "Hemşirelerin algıladıkları sosyal destek ile problem çözme becerisi arasındaki ilişki”". Gümüşhane Üniversitesi Sağlık Bilimleri Dergisi, 4 (4), 574593.

29. Çinar, N, Sözeri, C, Sevil Şahin, S, Cevahir, R. and Say, M (2010). "Problem Solving Skills of The Nursing and Midwifery Students and Influential Factors". Rev. Eletr. Enf, 12 (4), 601606.

30. Altun, İ. (2003). "The Perceived Problem Solving Ability and Values of Student Nurses and Midwies". Nurse Educ Today, 23 (8), 575-584. 